\title{
Logarithmic vs. Linear Visualizations of COVID-19 Cases Do Not Affect Citizens' Support for Confinement
}

\author{
Semra Sevi, Université de Montréal* \\ Marco Mendoza Aviña, Université de Montréal \\ Gabrielle Peloquin Skulski, Université de Montréal \\ Emmanuel Heisbourg, Université de Montréal \\ Paola Vegas, Université de Montréal \\ Maxime Coulombe, Université de Montréal \\ Vincent Arel-Bundock, Université de Montréal \\ Peter Loewen, University of Toronto \\ André Blais. Université de Montréal
}

\section{THIS WORK IS CURRENTLY UNDER REVIEW}

In public health crises, the media and governments routinely share statistical analyses with the public. In the COVID-19 pandemic, the tool most commonly used to convey statistical information about the spread of the virus has been time-series graphs about the cumulative number of cases. When drawing such graphs, analysts have to make design decisions which can have dramatic effects on citizens' interpretations. Plotting the COVID-19 progression on a linear scale highlights an exponential "explosion" in the number of cases, whereas plotting the number of cases on a logarithmic scale produces a line with a modest-looking slope. Even if the two graphs display the exact same information, differences in visual design may lead people to different substantive conclusions. In this study, we measure the causal effect of different visualization design choices on Canadians' views about the crisis. We report results from a survey experiment conducted in April 2020 with a sample of 2500 respondents. We find that no matter how the information is presented, Canadians are united in supporting drastic confinement measures and in accepting that these measures will not be removed soon.

Keywords: data visualization; linear; logarithmic; COVID-19; coronavirus; survey experiment

\footnotetext{
*Corresponding author: semra.sevi@umontreal.ca
} 
The SARS-CoV-2 virus was first identified in Wuhan, China in late December 2019, and it quickly spread to many countries. By March 2020, the virus had triggered a global pandemic of coronavirus disease 2019, or COVID-19 (World Health Organization, 2020). In response to this crisis, governments have implemented unprecedented public health measures. The success of these policies will largely depend on the public's willingness to comply with new rules. A key factor in citizens' willingness to comply is their understanding of the data that motivate government action. In this study, we examine how different ways of presenting these data visually can affect citizen's perceptions, attitudes, and support for public policy.

The most common visual strategy to convey information about the spread of COVID-19 is to display a time-series graph of the cumulative number of cases (Figure 1). This type of graph has been used by media and governments all over the world. Indeed, the New York Times and the Financial Times have entire sections dedicated to updates on COVID-19 cases and deaths in both logarithmic and linear graphs (Financial Times 2020; Katz et al. 2020). The goal of this paper is to understand how two alternative ways of displaying time-series data affect citizens' perceptions and beliefs.

We measure the effect of data visualization on two important outcomes. The first is people's views about the tough measures that have been adopted by authorities. Do Canadians support the confinement policies? The second outcome of interest is people's relative pessimism about the prospect of an end to the ongoing crisis. When do Canadians think that they will be allowed to go back to work? These two outcomes are substantively important, because they capture the twin goals of public communication: conveying a sense of urgency to people who face a major crisis, without making them too pessimistic.

\section{Time Series Graphs with Linear or Logarithmic Scales}

Many visualization strategies can be used to track the evolution of a public health crisis. During the 2019-2020 pandemic, the most common approach is to plot a simple line to represent the cumulative number of COVID-19 cases over time. Such plots are easy to draw and interpret, but their simplicity can be deceptive. Indeed, data analysts must make several discretionary choices when they draw time series plots. One important decision concerns the scale on which the variable of interest is displayed.

The default choice for most time series plots is to use a linear scale on the vertical axis. On that scale, the variable increases additively as it rises. In the left panel of Figure 1, we see that the visual distance between 0 and 2500 is exactly the same as the visual distance between 2500 and 5000. Graphs on a linear scale are typically the first and most common visualization tool taught to children.

An alternative way to plot time series data is to use a logarithmic scale on the vertical axis. On that scale, the variable increases multiplicatively as it rises. In the right panel of Figure 1, we see that the visual distance between 10 and 100 is the same as the visual distance between 100 and 1000, that is, a 10fold increase. ${ }^{\dagger}$ The slope of a log-scaled graph measures the relative change in the variable of interest. ${ }^{\ddagger}$ This makes it a powerful tool to assess growth rates, which are particularly meaningful in the context

\footnotetext{
+ Analysts can use logarithms with a different base. For instance, values on the $y$-axis could increase by multiples of 2 instead of 10 .

¥ A mathematical identity ensures that the difference between the log number of cases at time $t$ and the log number of cases at time $t-1$ is equal to the log of the ratio between those two quantities: $\log \left(\right.$ Cases $\left._{t}\right)-\log \left(\right.$ Cases $\left._{t-1}\right)=\log \left(\right.$ Cases $_{t} /$ Cases $\left._{t-1}\right)$.
} 
of a global health crisis. For instance, the right panel of Figure 1 makes it easy to see that, in midMarch 2020, it took just over one week for the number of confirmed COVID-19 cases to increase by a factor of 10. Another reason to use log-scale graphs is that they tend to pull extreme values toward the middle of the distribution. This can be useful when the magnitude of a variable changes dramatically. Finally, log-scale graphs are appropriate when the underlying process that we are modelling is exponential. For example, when the basic reproduction number of an infection $\left(\mathrm{R}_{0}\right)$ is greater than 1 , the number of cases can increase exponentially. On a log-scale, this exponential increase appears as a straight line, which only bends when the growth rate changes. These properties explain why this visualization strategy is so popular in epidemiology.

Figure 1: Two time-series plots showing the cumulative number of COVID-19 cases in Canada up to April 2, 2020. The left panel displays data on a linear scale. The right panel displays data on a logarithmic scale.
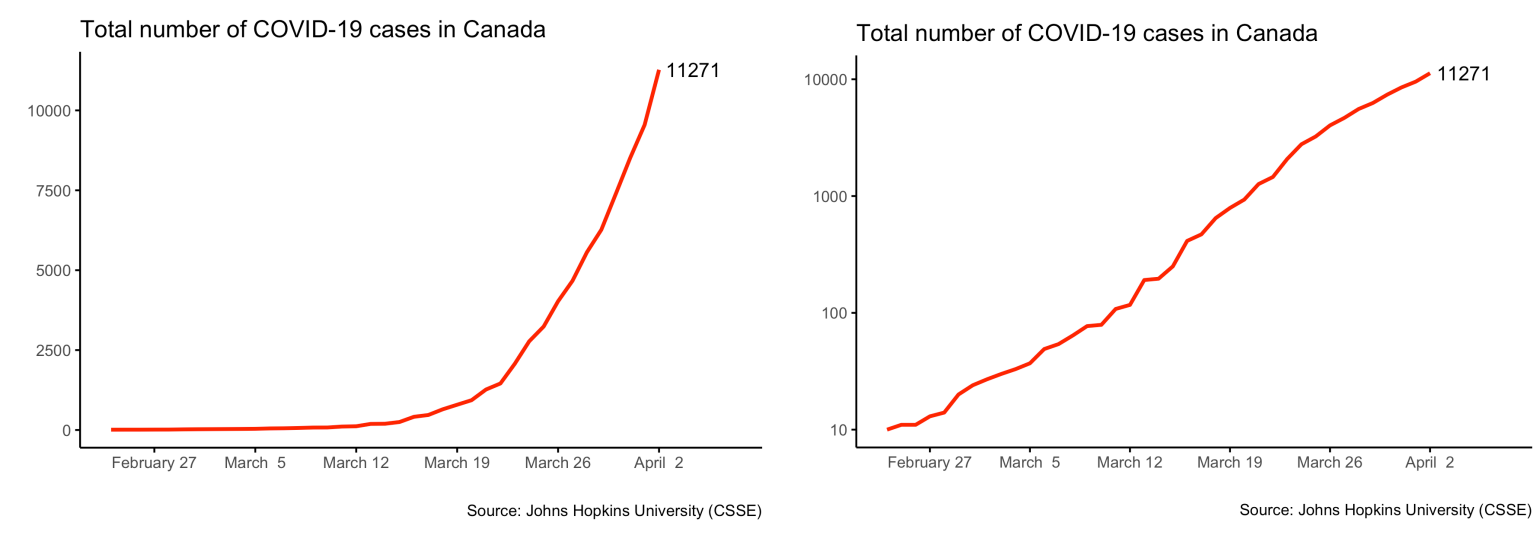

Graphs drawn on a logarithmic scale hold many advantages, but it is not clear if ordinary citizens have the skills required to properly interpret them. Most importantly, we do not know what differential effect linear and logarithmic representations of the data have on the perceptions and beliefs of the general public.

As can be seen in Figure 1, the increase in the number of cases with COVID-19 seems much more dramatic when it is displayed on a linear scale, because the curve emphasizes the exponential "explosion" of the phenomenon. In contrast, the logarithmic scale shows a straight line with a much flatter slope. Even if the two plots display precisely the same information, citizens could react differently when reading them. Do people become more supportive of the authorities' strong public health measures when they are shown "dramatic" linear plots? Are citizens more optimistic when they read "tame" logarithmic plots?

\section{Data and Methods}

To answer these questions, we conducted a survey experiment with a sample of 2,500 Canadians interviewed between April 3 and April 5, 2020. This sample is nationally representative by age, gender, language, and province. 
Each participant was randomly assigned to one of three groups: a control or one of two treatments. The control group received no information about the outbreak. Each treatment group was shown a time series plot of the cumulative number of confirmed COVID-19 cases in Canada. The first treatment group saw a linear graph, and the second treatment group a logarithmic graph.

Figure 1 shows the two graphs presented to respondents on the first day of the survey. Those two graphs are quite different. Whereas both display the cumulative number of cases since the beginning of the outbreak, the linear graph (left) conveys a clear a message of crisis: things are worse than before, and the pace is accelerating. In contrast, the smoother trend in the logarithmic graph is much less dramatic. If visual presentation matters, we should observe differences in the experimental groups' reactions

Importantly, the two graphs we used are very similar to graphs published in major newspapers, by epidemiologists, and by government agencies. An examination of the Globe and Mail (Agius et al. 2020), Toronto Star (Tulk et al. 2020) and CBC (CBC 2020) daily trackers suggests that linear treatments are more common, however in press conferences held by Ontario and British Columbia on April 32020 and March 272020 respectively (Government of Ontario, 2020; BC Centre for Disease Control, 2020) the data were presented on a logarithmic scale. Accordingly, while presenting individuals with a single visual image, embedded in a survey, may seem to be a weak treatment, it closely maps onto how individuals experience and consume similar information when reading a newspaper. The construct validity of our experiment is arguably quite high.

To measure the dependent variables, members of the treatment and control groups were asked two questions. First, we asked them if they support or oppose the governments' instruction to remain at home (scale of 0 to 10). Second, we asked respondents when they expect the government to allow nearly everyone back to work (see the appendix for complete question wordings).

The main question that we address is whether it makes a difference whether people are shown a linear or a logarithmic scale. Those who are shown the logarithmic scale are presented with a slope that is less steep. As a consequence, they may perceive the contagion to be less serious than those who were shown the linear graph and for that reason they may be more optimistic about when things could come back to normal.

\section{Results}

Our findings are easy to summarize. For both dependent variables (pessimism and support), there is essentially no difference between the two treatment groups, or between the treatment groups and the control group. Showing a graph or not does not make a difference, and people react the same way whether they are shown a graph with a logarithmic or a linear scale. We discuss the implications of these results below.

Before doing so, it is important to note the extraordinary support for confinement. 54\% of the respondents say they fully support, that is they give a score of 10 on a 0 to 10 scale, the stringent measures that force most people to stay home. Furthermore, a strong majority of Canadians believe

\footnotetext{
$\S$ Graphs were updated daily using data from Dong, Du \& Gardner (2020).
} 
that confinement will have to last at least two more months; only $10 \%$ of respondents expect most people to come back to work in April or May.*

Do citizens' reactions vary across socio-demographic groups? The mortality rate is much higher among the eldest, and so they may be particularly supportive of confinement measures, especially given those who are retired and therefore are not prevented from working. Likewise, women are generally more favourable to social protection measures (Gidengil 1995), and we may predict that they are more willing to accept the necessity of confinement. Similarly, the more educated may be more strongly exposed to the unanimous elite message that radical measures are needed (Zaller 1992). Finally, the severity of the contagion as well as the way the authorities communicate with the public vary substantially across provinces and therefore there could be important variations across the regions. Quebec, in particular, has been the most strongly affected, the provincial government was the first to adopt stingiest confinement measures, the provincial Premier and the now famous Doctor Horacio Arruda have been widely acclaimed as performing extremely well in their daily press conferences. We may thus predict Quebeckers to be more strongly favourable to confinement, and more prone to accept the fact that it will take months before most people will come back to work.

Again, our findings are basically nil, as can be seen in Figure 2. Canadians' reactions vary very little by age, gender, education, or region. Most of the time, the differences between the various groups are not statistically significant (despite the fact that we have a big sample) and where they are the magnitude of the effect is quite small. The eldest are more supportive of confinement but the youngest are also strongly in favour. Quebeckers are slightly more optimistic about when they will be able to come back to work, but the absence of regional difference in support for confinement is even more striking.

We interpret these findings as indicators of the stunning success of the public health experts and governments in convincing citizens that the measures that are taken are necessary and may have to last for at least some months. This is not a 'nice' message. Spontaneously, people are inclined to resist such an unpleasant message. But in the end, Canadians are accepting the bad news. This is a case of remarkable success. The elite message is accepted. Cynicism and mistrust are at bay.

We suspect that this is why our treatments did not have any effect. Canadians have come to believe that this is a huge crisis and that the authorities are doing what is necessary. Providing them with visual information did not modify these views.

\footnotetext{
** We must acknowledge the possibility that some respondents without clear opinion on the issue may have been inclined to choose the middle options.
} 
Figure 2: Subgroup averages for the two outcome variables by treatment group, region, gender, education and age.

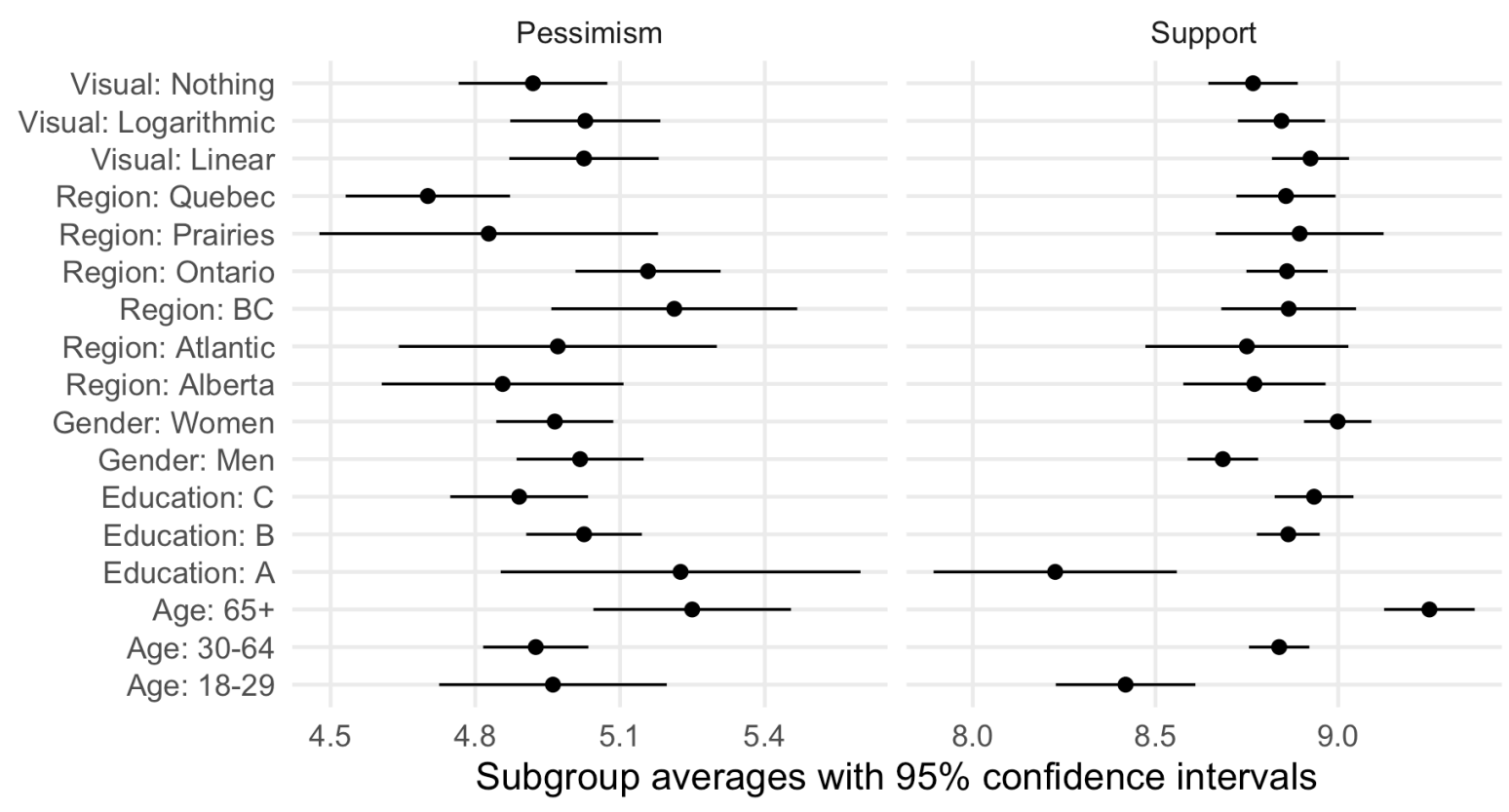




\section{References}

Agius, Jeremy, Danielle Webb and Evan Annett, "How many coronavirus cases are there in Canada, by province, and worldwide? The latest maps and charts", The Globe and Mail, April 9. 2020 ,

https://www.theglobeandmail.com/canada/article-coronavirus-cases-canada-world-mapexplainer/\#most-affected-countries-nav

BC Centre for Disease Control. 2020. COVID-19: Critical Care and Acute Care Hospitalization Modelling. https://news.gov.bc.ca/files/COVID19_TechnicalBriefing_Mar27_2020.pdf?fbclid=IwAR0 VLdGpg0FK7n32hkvnXf-TimpMcoq7PUDatD_iBTT6GKh0wmmz5hXeomE

CBC. 2020. "Tracking the coronavirus." CBC/Radio-Canada. https://newsinteractives.cbc.ca/coronavirustracker/

Dong, Ensheng, Hongru Du, and Lauren Gardner. 2020. “An Interactive Web-Based Dashboard to Track COVID-19 in Real Time." The Lancet Infectious Diseases.

Financial Times. 2020. Coronavirus tracked: the latest figures as the pandemic spreads. The Financial Times. https://www.ft.com/coronavirus-latest

Gidengil, Elisabeth. 1995. "Economic Man-Social Woman? The Case of the Gender Gap in Support for the Canada-US Free Trade Agreement." Comparative Political Studies 28(3): 384-408.

Government of Ontario. 2020. "COVID-19 Modelling. Toronto: Government of Ontario." https://windsorite.ca/wp-content/uploads/2020/04/COVID-19-Technical-BriefingFriday-April-4-2020.pdf

Katz, Josh, Kevin Quealy and Margot Sanger-Katz. "Coronavirus in the U.S. : How Fast It's Growing," The New York Times, April 9th, 2020, https://www.nytimes.com/interactive/2020/04/03/upshot/coronavirus-metro-areatracker.html?action $=$ click\&module $=$ moreIn\&pgtype $=$ Article\&region $=$ Footer

Oxford COVID-19 Government Response. "Oxford COVID-19 Government Response Tracker" Accessed on April 09, 2020. https://www.bsg.ox.ac.uk/research/research-projects/oxfordcovid-19-government-response-tracker

Radio-Canada. 2020. Évolution de la COVID-19. CBC/Radio-Canada. https://ici.radio-canada.ca/info/2020/coronavirus-covid-19-pandemie-cas-carte-maladiesymptomes-propagation/

Rothman, Kenneth J., Lauren A. Wise and Elizabeth E. Hatch. 2011. "Should Graphs of Risk or Rate Ratios be Plotted on a Log Scale?” American Journal of Epidemiology 174(3): 376-377.

Treble, Patricia. 2020. Coronavirus in Canada: These charts show how our fight to 'flatten the curve' is going. Maclean's, April 9, 2020. https://www.macleans.ca/society/health/coronavirus-in-canada-these-charts-show-howour-fight-to-flatten-the-curve-is-going $/$ 
Tulk, Cameron, Nathan Pilla, Andres Plana and McKenna Deighton, "The latest COVID-19 data from Canada and around the world. Check here for updates on cases and deaths", The Toronto Star, April 9, 2020,

https://www.thestar.com/news/canada/the-latest-covid-19-data-from-canada-and-aroundthe-world-check-here-for-updates-on-cases-and-deaths.html

World Health Organization. "WHO Director-General's opening remarks at the Mission briefing on COVID-19 - 12 March 2020, 2020." Accessed April 09, 2020.

https://www.who.int/dg/speeches/detail/who-director-general-s-opening-remarks-at-themission-briefing-on-covid-19---12-march-2020.

Zaller, John. 1992. The Nature and Origins of Mass Opinion. Cambridge: Cambridge University Press. 


\section{Appendix}

Figure 3: Distribution of responses for the pessimism and support variables

When do you think that governments will allow nearly everyone to go back to work?

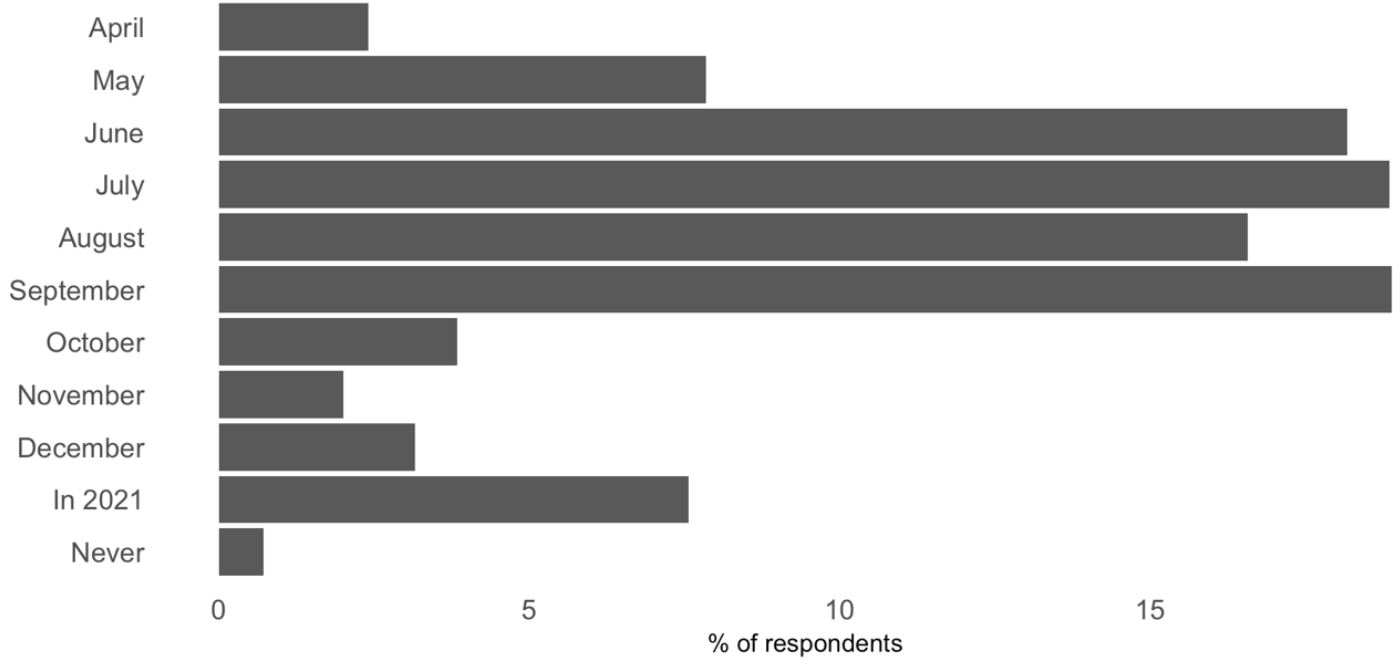

Because of the COVID-19 pandemic, governments are asking everyone to stay home, except for strictly essential work and basic necessities like grocery shopping. How strongly do you support or oppose that decision?

0: I fully oppose

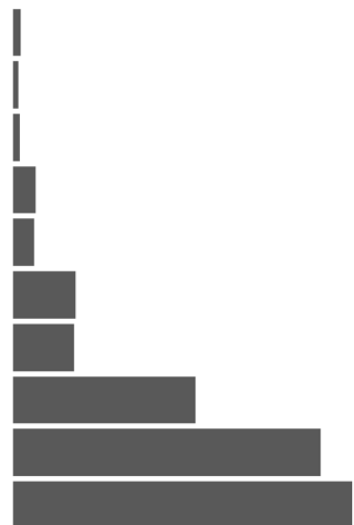

10: I fully support

0
20

$\%$ of respondents
40

Survey conducted April 3-7 2020. N = 2500 
Table 1: Full results by experimental condition, age group, region, and gender (OLS regressions)

\begin{tabular}{|c|c|c|c|c|c|c|c|c|c|c|}
\hline & \multicolumn{5}{|c|}{ Support (mean=8.84, sd=1.71) } & \multicolumn{5}{|c|}{ Pessimism (mean=4.99, sd=2.28) } \\
\hline & Graphs I & Gender I & Age I & Region I & $\begin{array}{c}\text { Education } \\
\mid\end{array}$ & Graphs II & Gender II & Age II & Region II & $\begin{array}{c}\text { Education } \\
\text { II }\end{array}$ \\
\hline \multirow[t]{2}{*}{$\begin{array}{l}\text { Visual: } \\
\text { Logarithmic }\end{array}$} & -0.079 & & & & & 0.003 & & & & \\
\hline & $(0.084)$ & & & & & $(0.112)$ & & & & \\
\hline \multirow[t]{2}{*}{ Visual: Nothing } & $-0.157^{*}$ & & & & & -0.106 & & & & \\
\hline & $(0.083)$ & & & & & $(0.111)$ & & & & \\
\hline \multirow[t]{2}{*}{ Gender: Women } & & $0.314^{\star \star \star}$ & & & & & -0.052 & & & \\
\hline & & $(0.068)$ & & & & & $(0.091)$ & & & \\
\hline \multirow[t]{2}{*}{ Age: $30-64$} & & & $0.420 \star \star \star$ & & & & & -0.036 & & \\
\hline & & & $(0.093)$ & & & & & $(0.126)$ & & \\
\hline \multirow[t]{2}{*}{ Age: $65+$} & & & $0.831^{\star \star \star}$ & & & & & $0.289 *$ & & \\
\hline & & & $(0.115)$ & & & & & $(0.155)$ & & \\
\hline \multirow[t]{2}{*}{ Education: B } & & & & & $0.638^{\star \star \star}$ & & & & & -0.200 \\
\hline & & & & & $(0.137)$ & & & & & $(0.183)$ \\
\hline \multirow[t]{2}{*}{ Education: C } & & & & & $0.708^{\star \star \star}$ & & & & & $-0.335^{*}$ \\
\hline & & & & & $(0.141)$ & & & & & $(0.189)$ \\
\hline \multirow[t]{2}{*}{ Region: Quebec } & & & & 0.086 & & & & & -0.155 & \\
\hline & & & & $(0.125)$ & & & & & $(0.166)$ & \\
\hline \multirow[t]{2}{*}{ Region: Atlantic } & & & & -0.021 & & & & & 0.114 & \\
\hline & & & & $(0.166)$ & & & & & $(0.220)$ & \\
\hline \multirow[t]{2}{*}{ Region: Ontario } & & & & 0.089 & & & & & $0.301 *$ & \\
\hline & & & & $(0.116)$ & & & & & $(0.155)$ & \\
\hline \multirow[t]{2}{*}{ Region: Prairies } & & & & 0.124 & & & & & -0.029 & \\
\hline & & & & $(0.163)$ & & & & & $(0.217)$ & \\
\hline \multirow[t]{2}{*}{ Region: BC } & & & & 0.094 & & & & & $0.356^{*}$ & \\
\hline & & & & $(0.138)$ & & & & & $(0.184)$ & \\
\hline \multirow[t]{2}{*}{ Intercept } & $8.924 * \star \star$ & $8.684^{\star \star \star}$ & $8.418^{\star \star \star}$ & $8.771^{\star \star \star}$ & $8.225^{\star \star \star}$ & $5.025^{\star \star \star}$ & $5.017 \star \star \star$ & $4.961^{\star \star \star}$ & $4.857^{\star \star \star \star}$ & $5.225^{\star \star \star}$ \\
\hline & $(0.059)$ & $(0.049)$ & $(0.084)$ & $(0.102)$ & $(0.129)$ & $(0.079)$ & $(0.065)$ & $(0.112)$ & $(0.136)$ & $(0.173)$ \\
\hline Num.Obs. & 2499 & 2499 & 2499 & 2499 & 2499 & 2499 & 2499 & 2499 & 2499 & 2499 \\
\hline R2 & 0.001 & 0.008 & 0.021 & 0.001 & 0.010 & 0.000 & 0.000 & 0.003 & 0.008 & 0.002 \\
\hline Adj.R2 & 0.001 & 0.008 & 0.020 & -0.001 & 0.009 & -0.000 & -0.000 & 0.002 & 0.006 & 0.001 \\
\hline AIC & 9769.6 & 9749.9 & 9721.4 & 9777.8 & 9747.6 & 11210.7 & 11209.6 & 11204.6 & 11198.4 & 11208.0 \\
\hline BIC & 9792.9 & 9767.4 & 9744.7 & 9818.6 & 9770.9 & 11234.0 & 11227.1 & 11227.9 & 11239.1 & 11231.3 \\
\hline Log.Lik. & -4880.811 & -4871.960 & -4856.698 & -4881.909 & -4869.821 & -5601.356 & -5601.809 & -5598.309 & -5592.179 & -5600.017 \\
\hline
\end{tabular}


Exact wording of the questions:

Because of the COVID-19 epidemic, governments are asking everyone to stay home, except for strictly essential work and basic necessities like grocery shopping. How strongly do you support or oppose that decision? (0 to 10 scale; I fully oppose to I fully support)

When do you think that governments will allow nearly everyone to go back to work?

April 2020

May 2020

June 2020

July 2020

August 2020

September 2020

October 2020

November 2020

December 2020

Sometime in 2021

Never 